$\begin{array}{cl}\begin{array}{c}\text { Revue } \\ \text { de I'histoire } \\ \text { des religions }\end{array} & \text { Revue de l'histoire des religions } \\ & \text { Genève, refuge et migrations (XV|e-XVIIe siècles) }\end{array}$

\title{
Alain DIERKENS, Jean-Philippe SCHREIBER (dir.), Le blasphème: du péché au crime
}

Bruxelles, Éditions de l'Université de Bruxelles (« Problèmes d'histoire des religions ", 21), 2012

\section{Patrick Henriet}

\section{OpenEdition Journals}

\section{Édition électronique}

URL : http://journals.openedition.org/rhr/8355

DOI : 10.4000/rhr.8355

ISSN : 2105-2573

\section{Éditeur}

Armand Colin

Édition imprimée

Date de publication : 1 mars 2015

Pagination : 88-91

ISBN : 9782200929657

ISSN : 0035-1423

Référence électronique

Patrick Henriet, «Alain Dierkens, Jean-Philippe Schreiber (dir.), Le blasphème : du péché au crime », Revue de l'histoire des religions [En ligne], 1 | 2015, mis en ligne le, consulté le 22 septembre 2020. URL : http://journals.openedition.org/rhr/8355 ; DOI : https://doi.org/10.4000/rhr.8355

Ce document a été généré automatiquement le 22 septembre 2020.

Tous droits réservés 


\title{
Alain DIERKENS, Jean-Philippe SCHREIBER (dir.), Le blasphème : du péché au crime
}

\author{
Bruxelles, Éditions de l'Université de Bruxelles (« Problèmes d'histoire
} des religions », 21), 2012

\section{Patrick Henriet}

\section{RÉFÉRENCE}

Alain DIERKENS, Jean-Philippe SCHREIBER (dir.), Le blasphème : du péché au crime, Bruxelles, Éditions de l'Université de Bruxelles (« Problèmes d'histoire des religions », 21), 2012, $24 \mathrm{~cm}, 178$ p., $20 €$, ISBN 978-2-8004-1520-8.

1 Dans le Don Juan de Molière, le personnage éponyme propose un louis d'or à un pauvre qui lui demandait l'aumône en se proposant de prier pour lui, mais à la condition que celui-ci accepte de jurer :

Le pauvre: Je vous assure, Monsieur, que le plus souvent je n'ai pas un morceau de pain à mettre sous les dents.

Don Juan : Voilà qui est étrange, et tu es bien mal reconnu de tes soins ; ah, ah, je m'en vais te donner un louis d'or tout à l'heure, pourvu que tu veuilles jurer.

Le pauvre: Ah, Monsieur, voudriez-vous que je commisse un tel péché ?

Don Juan : Tu n'as qu'à voir si tu veux gagner un louis d'or ou non, en voici un que je te donne si tu jures, tiens il faut jurer.

Le pauvre: Monsieur! Sganarelle : Va, va, jure un peu, il n'y a pas de mal. Don Juan : Prends, le voilà, prends te dis-je, mais jure donc. Le pauvre : Non Monsieur, j'aime mieux mourir de faim. Don Juan : Va, va, je te le donne pour l'amour de l'humanité [...]

2 Cette scène célèbre, citée par Manuel Couvreur dans la préface de ce volume (mais dans une version quelque peu différente), gênait et fut longtemps censurée. Elle n'est 
pourtant pas contraire à la religion, puisque le pauvre refuse le blasphème qu'on voudrait lui imposer et puisqu'il se voit tout de même, peut-être même pour cela même, récompensé. Elle rappelle en tout cas l'extrême sensibilité d'une question, celle du blasphème et du sacrilège, qui traverse les siècles et les religions. Le présent livre, fruit d'une réflexion commune à des historiens et à des juristes, aborde cette question en une douzaine d'articles qui, s'ils offrent des approches partielles et laissent de côté d'immenses pans chronologiques (tel le Moyen Âge), n'en proposent pas moins de fort intéressantes pistes de réflexion. Du point de vue de l'Histoire, outre la vaste fresque dressée par Alain Cabantous pour les $\mathrm{xVI}^{\mathrm{e}}$ - $\mathrm{xx}^{\mathrm{e}}$ siècles, on trouvera des études consacrées au rapport entre blasphème et idolâtrie dans l'Antiquité juive, grecque et chrétienne (Baudoin Decharneux), au discours des Pères de l'Église et à son rapport avec le Nouveau Testament (Fabien Bobilio), au blasphème dans la Torah et dans le Talmud (Thomas Gergely), à sa caractérisation comme délit politique au xvI siècle (Monique Weis), à sa perception dans la tradition protestante (Valentine Zuber), enfin au recul de la liberté d'expression dans le cinéma depuis les années 1960-1970 (Anne Morelli). Du point de vue du droit, sont abordés le traitement du blasphème dans une perspective comparée législation canonique/législation séculière (Brigitte Basdevant), la tendance des législations européennes à rechercher l'implicite et le sous-entendu dans les discours (Louis-Léon Christians), la protection du sentiment religieux en Suisse, en Allemagne et en Italie (Vincenzo Pacillo), enfin le traitement par la loi du rapport liberté d'expression/blasphème en Europe et aux États-Unis (Guy Haarscher). Le schéma général qui se dégage de cet ensemble est celui d'une sorte de laïcisation du blasphème dans les pays occidentaux, avec un passage du péché au crime (voir l'introduction de Jean-Philippe Schreiber sur la "criminalisation du péché»). Le volume réserve ici et là un certain nombre de surprises, la moindre n'étant pas que la notion de blasphème reste juridiquement présente dans nombre de pays démocratiques (Allemagne, Autriche, Danemark, Finlande, Irlande, Espagne, Italie, Norvège, Pays-Bas, Pologne, Suisse, Royaume-Uni, mais pour l'Église anglicane seulement dans ce dernier cas : Salman Rushdie ne peut donc y être poursuivi pour blasphème). On ne sait pas toujours qu'en Alsace-Lorraine, non soumise à la loi de 1905, « celui qui aura causé un scandale en blasphémant publiquement contre Dieu par des propos outrageants, ou aura publiquement outragé un des cultes chrétiens ou une communauté religieuse établie [...] sur le territoire de la Confédération et reconnue comme corporation, ou les institutions ou cérémonies de ces cultes, ou qui, dans une église ou un autre lieu consacré à des assemblées religieuses, aura commis des actes injurieux et scandaleux, sera puni d'un emprisonnement de trois ans au plus ». De là à dire que seule la nature des peines a changé depuis saint Louis serait évidemment abusif, mais cette liste et ce texte invitent à nuancer au moins sur le plan du droit l'opposition entre les pays occidentaux et les autres. Pour ce qui est des conceptions, l'évolution la plus étonnante est assurément celle des églises protestantes, qui sont progressivement passées d'une persécution des blasphémateurs au $\mathrm{XVI}^{\mathrm{e}}$ siècle (cas bien connu de Michel Servet) à une quasi-valorisation dans certains cas («Il n'y a que les blasphèmes qui soient vrais », écrivait Albert Schweitzer) ou à une indifférence le reste du temps (d'où cette remarque de Raphaël Picon : « Une religion pour laquelle rien ne serait blasphématoire [le protestantisme ?] est peut-être une religion pour laquelle rien n'est sacré... »).

3 Mais les religions n'ont pas le monopole de la constitution de sphères, de thèmes ou de réalités intouchables. Les démocraties se sont donc dotées de "réalités notionnelles devenues tout autant fondatrices qu'intangibles» (Alain Cabantous). Il n'est pas 
possible de tout dire : en témoigne, au moment où ces lignes sont écrites, l'interdiction des spectacles antisémites de l'humoriste français Dieudonné. Il y a là une sorte de laïcisation du blasphème, de transfert d'un sacré religieux aux valeurs de la République, aux droits de l'homme et à l'antiracisme. On sait bien depuis Marcel Gauchet que les sociétés modernes et démocratiques ont converti le « religieux » plus qu'elles ne l'ont éliminé. Or cette réalité pose aujourd'hui un problème majeur : comment expliquer l'interdiction qui pèse sur certains discours (ainsi de toute parole raciste) tout en autorisant le "blasphème » ou ce qui est perçu comme tel (ainsi la publication des caricatures de Mahomet dans Charlie Hebdo)? On connaît la réponse, telle que la rappelle Jean-Philippe Schreiber en conclusion: il est licite de s'en prendre à une religion, mais il ne l'est pas de s'attaquer à la dignité des individus et plus généralement à la personne humaine. Le problème est alors de savoir comment convaincre du bienfondé de cette distinction des croyants qui, précisément parce qu'ils croient en un dieu, ne peuvent admettre qu'il est moins grave de s'en prendre à celui-ci qu'à telle ou telle personne ou à telle ou telle communauté, seulement humaine. Il y a là une sorte d'aporie majeure à laquelle se trouvent confrontées nos sociétés modernes, aporie que personne ne sait aujourd'hui résoudre.

Un mot pour finir sur l'image de couverture, la sulfureuse tentation de saint Antoine dessinée au pastel par Félicien Rops en 1878. Une femme nue gracieusement cambrée y a pris la place du Christ sur la croix du calvaire et sourit à un saint Antoine horrifié. La perception de cette œuvre comme blasphématoire par la majorité des catholiques ne fait aucun doute. Mais où commence et où s'arrête le blasphème ? Doit-on prendre en compte l'intention du blasphémateur? Félicien Rops expliquait ainsi son œuvre dans une lettre à son ami François Taelemans : «le sujet est facile à comprendre; le bon Saint Antoine, poursuivi par les visions libidineuses, se précipite vers son prie-Dieu, mais pendant ce temps-là, Satan - un drôle de moine rouge - lui fait une farce ; il lui a ôté son Christ de la croix et l'a remplacé par une belle fille, comme les diables qui se respectent en ont toujours sous la main. Tout cela au fond n'est qu'un prétexte à peindre d'après nature une belle fille qui nous faisait manger, il y a un an déjà ! des œufs à la tripe, à la mode de Touraine et qui, pour la première fois et après bien des insistances a bien voulu poser pour son vieux Fély [...]. Surtout éloigne de la tête des gens toute idée d'attaque à la religion ou d'éroticité ". Commentant cette même Tentation, Freud, dans son analyse de la Gradiva de Jensen, y voyait un bel et précoce exemple de discours sur le refoulement: «Le graveur a choisi le cas exemplaire du refoulement dans la vie des saints et des pénitents. Un moine ascète s'est réfugié sûrement pour fuir les tentations du monde - près de l'image du Sauveur crucifié. Alors cette croix s'affaisse comme une ombre et, rayonnante, s'y substituant, s'élève à sa place l'image d'une femme nue aux formes épanouies, également dans la position du crucifiement. D'autres peintres, dont la pénétration psychologique était moindre, ont placé, dans les représentations analogues de la tentation, le péché insolent et triomphant quelque part à côté du Sauveur sur la croix. Seul Rops lui a fait prendre la place du Sauveur lui-même sur la croix ; il paraît avoir su que le refoulé, lors de son retour, surgit de l'instance refoulante elle-même... » Le blasphème ou l'impossible consensus? 


\section{AUTEURS}

\section{PATRICK HENRIET}

École Pratique des Hautes Études, Paris. 